\title{
Enterprise Resource Planning governamental: a percepção dos servidores atuantes no Projeto Ciclo do Ministério da Justiça quanto à implementação
}

\author{
André Souza de Sena \\ Universidade de Brasilia (UnB) \\ Patricia Guarnieri \\ Universidade de Brasilia (UnB)
}

\begin{abstract}
Indubitavelmente, a implementação de sistemas de gestão integrada é fator consolidado em empresas privadas; no entanto, em empresas públicas é relativamente recente e inovadora. Em 2009, o Ministério da Justiça (MJ) foi um dos pioneiros ao firmar parceria com a Universidade Federal do Rio Grande do Norte (UFRN) para a implantação de sistemas de gestão integrada. Com o decorrer dos processos de implementação surge a necessidade de identificar se o acordo surtiu os efeitos a que se destinou, bem como é pertinente a análise da implementação de um Enterprise Resource Planning (ERP) governamental em uma empresa pública, haja vista que existe uma tendência de que se repita em outras instituições governamentais. Assim, o principal objetivo deste artigo é identificar a percepção dos usuários quanto ao processo de implementação de sistemas integrados de gestão vinculados ao Projeto Ciclo, no âmbito da Secretaria Executiva do MJ, destacando suas principais dificuldades e benefícios. A fim de atingir o objetivo da pesquisa foi realizada uma pesquisa quali-quantitativa, cujo procedimento técnico foi o estudo de caso. Verificou-se que os usuários do sistema reconhecem sua importância como apoio à tomada de decisão, que estão cientes do papel que desempenham no processo de implementação e que a tecnologia da informação (TI) é fundamental para se obter melhoria nos processos executados. Ademais, percebe-se os avanços que um ERP governamental pode proporcionar a empresas públicas, destacando-se o planejamento e a confiabilidade das informações.
\end{abstract}

Palavras-chave: apoio à tomada de decisão; ERP governamental; percepção dos usuários do sistema; Projeto Ciclo/MJ; sistemas de gestão integrada; tecnologia da informação.

Planificación de Recursos Empresariales gubernamental: la percepción de los servidores activos en el proyecto Ciclo del Ministerio de Justicia sobre la aplicación

Sin duda, la implementación de sistemas integrados de gestión ya es el factor consolidado en el sector privado, sin embargo, en las empresas públicas es relativamente reciente e innovadora. En 2009, el 
Ministerio de Justicia (MJ), fue uno de los pioneros en el establecimiento de una asociación con la Universidad Federal de Rio Grande do Norte (UFRN) para la implementación de sistemas integrados de gestión. En el curso de los procesos de ejecución hay una necesidad de identificar si el acuerdo ha tenido el efecto que se pretendía. El objetivo principal de este trabajo es identificar la percepción de los usuarios sobre el proceso de implementación de sistemas integrados de gestión relacionados con el proyecto Ciclo, dentro de la Secretaria Executiva del Ministerio de Justicia, destacando sus principales beneficios y las dificultades. Con el fin de lograr el objetivo se llevó a cabo la investigación cuali-cuantitativa, cuyo procedimiento técnico fue el estudio de caso. Se encontró que los usuarios reconocen la importancia del sistema como soporte para la toma de decisiones; que son conscientes de su papel en el proceso de implementación y que la tecnología de la información (TI) es crucial para el logro de mejoras en los procesos. Es evidente que el ERP puede proporcionar avances en las empresas públicas, especialmente con respecto a la planificación y la fiabilidad de la información.

Palabras clave: apoyo a la toma de decisiones; ERP gubernamental; percepción de los usuarios del sistema; Proyecto Ciclo/MJ; sistemas integrados de gestión; tecnología de la información.

Government Enterprise Resource Planning: the perception of active servers in the Cycle Project of the Ministry of Justice on the implementation

Undoubtedly the implementation of integrated management systems is already consolidated in private sector, however in public companies is relatively recent and innovative. In 2009, the Ministry of Justice, MJ, was one of the pioneers in establishing a partnership with the Federal University of Rio Grande do Norte (UFRN) for a development of integrated management systems. In the course of implementation processes arises the need to identify whether the agreement has had the effect that was intended and also, it is pertinent to analyze the implementation of an ERP into a public company, considering that there is a tendency to repeat in other government institutions. The main objective of this paper is to identify the users' perception regarding the process of implementation of integrated management systems linked to the Project Ciclo/MJ, emphasizing its benefits and challenges. In order to achieve the objective of the research was carried out an quali-quantitative research, whose technical procedure used was the case study. It was found that users of the system acknowledge its importance as a decision-making aid; they are aware of their role in the implementation process and that information technology (IT) is crucial to achieving improvements in processes. Also there are advances that an ERP can provide for the government-owned enterprises, especially the planning and reliability of information.

Keywords: Ciclo/MJ project; decision making aid; Governmental ERP; information technology; Integrated management systems; perception of system's users.

\section{Introdução}

Na década de 1990 houve uma profusão na adoção de modelos de gestão integrada, os quais eram suportados por sistemas Enterprise Resource Planning (ERP). A maior parte dos usuários era de grandes empresas com foco industrial. No entanto, pequenas e médias empresas têm aderido a esses sistemas com o propósito de profissionalizar sua gestão, além de uma maior adesão também por parte do setor comercial e de serviços, tais como empresas dos ramos financeiro, de saúde, de educação e do serviço público (Carvalho et al., 2009). Com 
recursos financeiros cada vez mais escassos e com o crescimento das expectativas dos cidadãos e cobrança por maior transparência, a administração pública brasileira tem enfrentado diversos desafios no aperfeiçoamento da gestão de seus processos. Nesse sentido, uma das soluções apontadas pelos especialistas é a adoção de sistemas integrados de gestão, como é o caso do ERP (Tricate, 2014). Nesse contexto, em 2009, o Ministério da Justiça (MJ) firmou parceria, via acordo de cooperação técnica, com base em redes colaborativas, com a Universidade Federal do Rio Grande do Norte (UFRN) para a implantação de sistemas de gestão integrada administrativa e de pessoas. O Projeto Ciclo, como foi denominado, envolveu o desenvolvimento de módulos específicos e a customização dos sistemas estruturantes por parte dos participantes do acordo, com base em sistemas de gestão administrativa e de pessoas, e a UFRN ficou responsável por identificar cada realidade peculiar dos parceiros e generalizar os módulos do sistema a todos os integrantes da rede de cooperação (Brasil, 2009). Assim, o ERP governamental compreende módulos e sistemas que operacionalizam os processos realizados por empresas do serviço público, com procedimentos amparados na legislação, de maneira integrada, cujo objetivo principal é aumentar a eficiência e transparência dos processos realizados.

Com o decorrer dos processos de implementação há a necessidade de identificar se o acordo de cooperação técnica surtiu os efeitos a que se destinou; ademais, é pertinente a pesquisa da implementação de ERPs governamentais, haja vista que é uma tendência em instituições públicas e a literatura ainda é escassa. Considerando que em empresas privadas a implementação de tais sistemas já está consolidada, existe a necessidade premente de estudos voltados à área pública no que tange aos benefícios e dificuldades desse processo. Principalmente quando se considera que, assim como as empresas privadas, as empresas públicas tendem a se especializar adotando novas práticas e tecnologias a fim de atender as expectativas dos usuários/cidadãos que se tornam cada vez mais exigentes.

O objetivo deste artigo é identificar a percepção dos usuários quanto ao processo de implementação do ERP governamental vinculado ao Projeto Ciclo/MJ, no âmbito da Secretaria Executiva do MJ, destacando-se os principais benefícios e dificuldades para uma empresa pública nesse processo.

Cabe ressaltar que o presente estudo de caso envolve a gestão de uma rede pública de cooperação voltada para o aperfeiçoamento das políticas públicas e melhores práticas de governança, racionalizando os gastos públicos e oferecendo maior publicidade dos atos dos agentes públicos. Ressalta-se que o intuito é o ganho de eficiência com a adoção do sistema integrado de informações (Brasil, 2009).

A fim de atingir o objetivo da pesquisa, foi realizada uma pesquisa aplicada, descritiva e quali-quantitativa, cujo procedimento técnico utilizado foi o estudo de caso. Os instrumentos de coleta de dados utilizados foram: i) análise documental; ii) questionário de pesquisa; e iii) observação direta. A análise documental baseou-se em documentos internos sobre o Projeto Ciclo/MJ e também em documentos oficiais disponibilizados na internet. A escolha dos respondentes da entrevista seguiu os critérios de acessibilidade e representatividade, os quais foram os gerentes do Projeto Ciclo/MJ. A observação direta se realizou com base nos principais 
processos realizados e na interação dos servidores com o sistema. Os resultados foram tabulados, tendo sua frequência analisada, e organizados sistematicamente por meio da técnica de análise categorial temática, calcada na análise de conteúdo proposta por Bardin (1977).

Com base nos resultados da pesquisa, verificou-se que os usuários do ERP governamental reconhecem a importância dos sistemas integrados de gestão, principalmente como apoio à tomada de decisão. Além disso, os usuários estão conscientes do Projeto Ciclo e da relevância da tecnologia da informação (TI) no processo de gestão. A fim de analisar a resistência do uso do ERP governamental, questionou-se os participantes do estudo sobre a usabilidade e sobre a utilização de outros sistemas não integrados, e verificou-se que existem alguns módulos ainda não homologados que dificultam a utilização plena do sistema; no entanto, os usuários reconhecem sua importância nas rotinas de trabalho. Constatou-se também que os sistemas integrados se constituem em ferramenta fundamental no processo de tomada de decisão, tendo como principais benefícios para as empresas públicas o acesso em tempo real e de forma integrada das informações, e a garantia da obtenção de informações confiáveis.

O presente artigo é dividido em oito seções. Na Seção 2 os principais trabalhos publicados recentemente sobre sistemas ERP são destacados; na Seção 3 são apresentados os principais aspectos dos sistemas e tecnologias da informação na gestão integrada e os sistemas ERP; na seção 4 são expostos os principais fatores que afetam o sucesso da implementação de sistemas ERP; a seção 5 expõe as principais características do ERP governamental; a seção 6 apresenta a classificação da pesquisa e o método empregado para coletar os dados; a seção 7 caracteriza o Projeto Ciclo/MJ, o papel dos parceiros das cooperações técnicas no projeto Ciclo-MJ, bem como os resultados obtidos com a aplicação dos questionários; enfim, a seção 8 apresenta as considerações finais e sugestões para estudos futuros.

\section{Revisão da literatura sobre sistemas Enterprise Resource Planning (ERP)}

Com base em uma revisão da literatura sobre os sistemas ERP e sua implementação, percebeuse que esse tema tem sido foco de recentes pesquisas. Villas e colaboradores (2006) realizaram um estudo de múltiplos casos, cujo objeto foi a empresa Petrobras, em suas diversas unidades de negócios, o que resultou em uma proposta de modelo conceitual para auxiliar a gestão das tecnologias de informação (TI) a fim de garantir o alinhamento de ações com as estratégias do negócio. Souza, Carvalho e Liboreiro (2006) realizaram uma análise das principais ferramentas de TI que determinam melhoria na criação e manutenção do supply chain management eficiente e, dentre elas, são destacados os sistemas ERP. Já AlBardin e AlBardin (2008) apresentam as dimensões do uso de TI e a relação entre os benefícios oferecidos pelo uso de TI e o desempenho empresarial.

Brodbeck e colaboradores (2009) buscaram configurar um processo de seleção, aquisição e implementação (SAI) de um ERP. Partindo da identificação de elementos técnicos relacionados com o ciclo de vida de um ERP e de elementos sociais relacionados com os interesses de grupos sociais encontrados na literatura, utilizou-se da grounded theory para acompanhar 
dois processos em dois estudos de caso buscando identificar uma configuração onde emergissem passos sequenciais em cada uma das fases do processo, além de aspectos sociais influentes em cada passo. Carvalho e colaboradores (2009) avaliaram a utilização do sistema ERP em uma indústria de médio porte, identificando os impactos na produtividade dos funcionários e na integração das informações.

Medeiros Jr., Perez e Shimizu (2009) classificaram os critérios de avaliação para utilização em sistema de apoio à decisão para posterior análise de aplicabilidade. A aplicação da técnica Delphi ocorreu em duas rodadas e, com base na opinião balizada de especialistas, foi possível reduzir e classificar os critérios em uma lista menor, para a seleção de um sistema do porte. Ghosh e Skibniewski (2010) investigaram a literatura atual sobre os fatores de sucesso e risco da implementação dos sistemas ERP, fornecendo assim uma explicação sistemática da complexidade envolvida em tal processo, cujo principal objetivo foi propor uma estrutura abrangente para a compreensão da implementação do ERP como um projeto complexo. Biancolino e colaboradores (2011) identificaram um conjunto de competências organizacionais inerentes à área da gestão de TI em organizações diretamente relacionadas com a gestão do ERP em sua fase de pós-implementação, agregando em seu valor de uso, percebido pelas principais áreas dessas organizações que são usuárias desse tipo de aplicativo.

Tripadalli, Fernandes e Machado (2011) desenvolveram um modelo teórico operacional de gestão da cadeia de suprimentos para o poder público com ênfase no processo de compras governamentais utilizando técnicas de TI, gestão de processos e comércio eletrônico. Helmy, Mohamed e Mosaad (2012) propuseram um modelo integrando os módulos do sistema ERP (contábil, vendas, controle de inventário, entre outros) com um sistema de business intelligence (BI) e ferramentas ETL, em um portal a fim de facilitar a coleta de informações de forma customizada.

Após a análise desses artigos, foi possível identificar algumas lacunas ainda existentes na literatura, como é o caso da implementação de sistemas ERP em empresas públicas e também no que se refere à percepção dos envolvidos nesse processo. O presente artigo se diferencia dos demais encontrados na literatura, cujo foco preponderante é dado à implementação dos sistemas ERP em empresas privadas. A contribuição deste artigo é a de auxiliar na superação dessas lacunas de pesquisa e demonstrar a percepção dos servidores envolvidos em um projeto de implementação de um ERP governamental vinculado ao Projeto Ciclo/MJ.

\section{Os sistemas e tecnologias da informação na gestão integrada e os sistemas ERP}

A implantação de programas de melhoria da gestão dos gastos públicos, conforme Tripadalli, Fernandes e Machado (2011), é normalmente viabilizada por meio da TI e deve vir acompanhada de ações voltadas à melhoria das compras e gestão de outros processos da cadeia de suprimentos do serviço público, possibilitando uma maior integração das informações geradas. Além disso, as empresas podem obter vantagens competitivas com o uso de TI; no entanto, é 
necessário que haja coerência entre as estratégias dessa implementação e do negócio (Villas, Fonseca e Macedo-Soares, 2006).

Os ERPs são sistemas transacionais no que se refere ao armazenamento de dados e processamento das tarefas rotineiras da empresa (Arozo, 2003). Um sistema ERP é considerado uma solução de software baseada na visão de gestão por processos de uma organização, a qual pressupõe que existe interação entre várias áreas e tem a finalidade de integrar de forma estreita todas as áreas e funções (Cavalcanti, 2001).

Corrêa, Gianesi e Caon (2001) e Turbam, Mclean e Wetherbe (2002) concordam que o objetivo do sistema ERP é suportar todas as informações gerenciais necessárias aos tomadores de decisões, as quais podem aumentar a produtividade e a satisfação dos clientes. Helmy, Mohamed e Mosaad (2012) afirmam que o principal propósito de um ERP é integrar todas as informações departamentais e funcionais em um único sistema, para facilitar a gestão da empresa. Além disso, com versões mais recentes do sistema ERP é possível a instalação de recursos adicionais possibilitando que fornecedores e clientes externos possam tomar parte nas decisões da cadeia de suprimentos por meio do sistema, abrangendo decisões relativas a: finanças, inventário, compras, gestão de pedidos, produção, entre outras.

Colângelo Filho (2001) acrescenta que, basicamente, existem três categorias de motivos que conduzem as empresas a implantar um ERP: i) negócios: aumento da lucratividade ou fortalecimento da competitividade; ii) legislação: atendimento às exigências legais; iii) tecnologia: atendimento às mudanças tecnológicas e exigências de parceiros de negócios.

No entanto, Tripadalli, Fernandes e Machado (2011) enfatizam que a implantação de projetos de integração de informações requer planejamento e infraestrutura de tecnologias de informação e comunicação (TICs) adequados; equipe bem treinada - incluindo os fornecedores - , e atos do governo que inspirem confiança nos usuários. Os autores ainda ressaltam a necessidade de um sistema para gerenciamento integrado de toda a cadeia de suprimentos do setor público, desenvolvido por um órgão central, para ser utilizado de forma compartilhada pelos órgãos subordinados. Souza, Carvalho e Liboreiro (2006) acrescentam que a análise das ferramentas de TI disponíveis para a gestão integrada de forma a permitir maior comunicação com os fornecedores, maior transparência, melhores resultados e satisfação dos clientes internos e externos é a chave para alcançar o sucesso organizacional.

Ademais, é importante ressaltar que, na implantação de um sistema de gestão, inicialmente, os custos dos processos aumentam, pois são inseridas novas atividades como: banco de preços; cadastros de bens e serviços; diligenciamento; gestão dos sistemas de registro de preços (SRP); gestão de estoques; sistemas financeiros; contábeis e fiscais; entre outros. No entanto, a longo prazo esses sistemas proporcionam grandes benefícios para a gestão integrada (Tripadalli, Fernandes e Machado, 2011). Souza, Carvalho e Liboreiro (2006) enfatizam que, ao utilizar os sistemas integrados para mapear as necessidades dos clientes, com as várias versões disponíveis no mercado de Customer Relationship Management/Electronic Data Interchange/Enterprise Resource Planning (CRM/EDI/ERP), cria-se a possibilidade de adaptar os processos internos e externos de forma a satisfazer mais adequadamente os usuários finais. 


\section{Fatores que afetam o sucesso da implementação dos sistemas ERP}

É importante considerar que, se na implementação os ERPs não forem considerados da perspectiva de sistemas integradores e como reais sistemas de informação, focando simplesmente sua implementação e possibilidades tecnológicas, os resultados não serão duradouros e efetivos (Carvalho et al., 2009). Ademais, os autores acrescentam que aspectos ligados aos sistemas ERP, como a capacidade de extração de informações de bases de dados diferentes, a formação de conhecimento para decisões de caráter operacional e a disponibilidade de informações para o planejamento estratégico, acabam por se tornar problemas dos sistemas já instalados (Carvalho et al., 2009).

Laudon e Laudon (2004) apontam alguns fatores diretamente responsáveis pelo sucesso ou fracasso da implementação de um sistema de informação, tais quais: o papel dos usuários no processo; o grau de apoio da alta administração; o nível de complexidade e risco; e a qualidade do gerenciamento do processo de implantação. Outrossim, dimensões para a avaliação do sucesso na implantação de sistemas de informação são apontadas por DeLone e McLean (1992): qualidade da informação e do sistema; grau de uso; satisfação do usuário; impacto no trabalho individual; e impacto nas organizações.

De acordo com Medeiros Jr., Perez e Shimizu (2009), fatores que facilitam o sucesso da implementação dos sistemas ERP podem ser pontuados: i) soluções mais bem desenvolvidas e mais amigáveis na parametrização; ii) melhor treinamento dos consultores; e iii) maior consciência das empresas quanto aos fatores críticos de sucesso na implantação dos sistemas.

Todavia, a escolha de um pacote ERP afeta todos os stakeholders e/ou grupos sociais que participam direta ou indiretamente dos negócios da empresa, o que torna essa decisão crítica para assegurar a criação e obtenção de informações confiáveis que apoiem a tomada de decisões na organização. Tais grupos interferem nas principais etapas do processo: seleção, aquisição e implementação, e podem afetar o seu sucesso ou fracasso (Brodbeck et al., 2009). Considerando que os sistemas ERP normalmente são precursores de contínuas mudanças na gestão dos processos de negócios das empresas, as capacidades ou competências organizacionais geralmente estão associadas à criação de valor (Biancolino et al., 2011).

Ademais, pressupõe-se que o valor alcançado pelo uso do sistema ERP é obtido não somente pelo uso integral do aplicativo, mas também pela maneira ou qualidade com a qual esse uso é realizado, o que pode ser mensurado por uma avaliação de cada usuário da organização (Clark Jr., Jones e Zmud, 2009). Li, Chen e Huang (2006) apontam os recursos humanos em TI como os atores preponderantes na sua implementação, devido a: (i) pessoas são importantes e podem afetar diretamente o sucesso ou o fracasso da implementação; (ii) as habilidades da equipe de implantação possuem maior influência sobre os efeitos do projeto; e (iii) somente uma equipe competente pode identificar os requisitos de um projeto complexo.

Nesse sentido, Bharadwaj (2000) ressalta que os recursos humanos em TI podem incluir as habilidades técnicas: programação; análise e desenho de sistemas; competência em tecnologias nascentes; e habilidades gerenciais, as quais são compostas por: gerenciamento efetivo das funções do sistema de informação; coordenação e interação com a comunidade 
de usuários; e gerenciamento de projeto e liderança. Essas competências organizacionais da área de TI proporcionam forte impacto nas rotinas de administração interna dos sistemas ERP e são essenciais para que as empresas obtenham equilíbrio operacional e construam bases informacionais robustas para uma gestão interna mais adequada e para a prestação de contas ao governo (Biancolino et al., 2011).

Segundo Lima e colaboradores (2010), a interoperabilidade e a integração de sistemas são atualmente os grandes desafios das organizações públicas. Para Daft (2008), os bancos de dados corporativos são ao mesmo tempo sistemas de gerenciamentos de informações, facilitando a tomada de decisões, e sistemas de controle e feedback, oferecendo informações para o controle das organizações.

Ao longo dos anos, o Programa de Governo Eletrônico Brasileiro (e-government) transformou as relações do governo com os cidadãos; cada vez mais estes buscam formas eficazes de transparência dos atos governamentais. Nesse contexto, o Projeto Ciclo/MJ, iniciado em 3 de julho de 2009, segundo Cooperação Técnica no 001/2009, conforme Brasil (2009), é uma ferramenta de apoio à tomada de decisão e se caracteriza como um ERP governamental. As principais características deste sistema são expostas na próxima seção.

\section{ERP governamental}

A nova administração pública se diferencia da administração pública burocrática por seguir os princípios do gerencialismo. Esse novo modelo de gestão deve enfatizar a profissionalização e o uso de práticas de gestão do setor privado (Paula, 2005). Nesse contexto, ressalta-se que a nova administração pública enfrenta diversos desafios que envolvem a escassez de recursos financeiros e o aumento das expectativas dos cidadãos, os quais podem ser superados ao se redesenhar os processos-chave e ao se reorganizar os processos internos. Aliado a isso, é essencial que a administração pública, a exemplo da iniciativa privada e de governos de diversos países, adote os sistemas integrados de gestão ERP, os quais conduzem a repensar a forma em que atividades estão sendo executadas (Tricate, 2014).

Os novos desafios impelem a administração pública para um ambiente de permanente transformação, no qual o uso da TI se tornou essencial no apoio à tomada de decisões nos níveis operacional, tático e estratégico. Sem dúvida, o cliente/cidadão espera das organizações públicas qualidade, eficiência e responsabilidade na utilização dos recursos de forma similar às empresas privadas. Aliados a essas exigências, diversos mecanismos de controle têm surgido a fim de propiciar a transparência no setor público, como é o caso do e-government (Moreno, Gobbo Jr. e Cavenaghi, 2007; Tripadalli, Fernandes e Machado, 2011; Abreu et al., 2012).

Denhardt (2008) afirma que o escopo da teoria da administração pública tem dois pontos de vista: o primeiro sendo parte do processo governamental e, portanto, tendo afinidade com a ciência política, da qual faz parte e, o segundo, que as organizações públicas são focadas como se fossem iguais às organizações privadas, sendo parte de uma teoria organizacional mais ampla. Pressupõe-se que as práticas adotadas na iniciativa privada podem e até mesmo 
devem ser adotadas em organizações públicas, considerando aumento da eficácia, otimização dos recursos e transparência. Nesse sentido enquadra-se a adoção dos sistemas integrados de gestão, como o ERP governamental.

De acordo com os dados de uma auditoria realizada pelo Tribunal de Contas da União (TCU, 2012a), de 57 empresas estatais pesquisadas em 2010, 49\% já possuíam sistemas ERP e 33\% planejavam adquiri-lo, o que demonstra o interesse dos gestores públicos na busca pela eficiência e maior confiabilidade nas informações para uso de recursos públicos. Os gastos aproximados com a aquisição desse tipo de sistemas, incluindo a implantação, manutenção e suporte, até 2010 foram de aproximadamente R\$ 1 bilhão, e há a tendência de aumento da utilização desse tipo de sistema na área pública.

Ressalta-se que, a partir de um ERP governamental, a visibilidade interna e externa do fluxo de processos em uma organização pública proporciona o conhecimento exato dos fatos administrativos e de seus motivadores, levando a organização a um nível superior de transparência, eliminando retrabalhos e garantindo confiabilidade aos gestores públicos na tomada de decisão, como já ocorre desde a década de 1990 na iniciativa privada (Tricate, 2014).

Nesse contexto, um ERP governamental permite que os macroprocessos de contabilidade, finanças, fiscal, suprimentos (aquisições), contratos e gerenciamento de documentos, manutenção, projetos, orçamento e recursos humanos sejam integrados e gerem informações aos gestores públicos em tempo real, de forma integrada. Destaca-se que as soluções ERP, normalmente, são produzidas por empresas especializadas que têm como foco o contínuo aprimoramento. É importante ressaltar que também há a possibilidade de desenvolvimento interno; no entanto, para isso requer-se uma equipe de TI altamente especializada, o que gera custos altos e fixos. Tricate (2014) destaca que as empresas especializadas oferecem soluções a um custo de manutenção fixo (normalmente anual), oferecem aos clientes suporte e constante atualização do produto com a disponibilização de novas versões.

Adicionalmente, ressalta-se que o desenvolvimento de customização de novas funcionalidades normalmente é necessário em um ERP governamental (TCU, 2012a). Entretanto, a contratação de sistemas ERP em empresas governamentais é mais bem justificada nos casos em que os processos de negócio implantados no núcleo operacional da solução contenham as regras determinadas pela legislação nacional, o que reduz custos com a frequente customização dos módulos (TCU, 2012a). Isso pode ser feito adaptando-se os sistemas estruturantes já existentes na plataforma do sistema ERP.

Assim, um ERP governamental pode ser projetado em módulos que possuem interligação entre si e deve ser desenvolvido a fim de integrar os sistemas estruturantes do governo federal: Sidor, Siop, Siafi, Siape, Siasg, Sidec, Sicon, ComprasNET, SIASGNet e SICAFWeb, de forma a contemplar processos-chave das áreas (Moreno, Gobbo Jr. e Cavenaghi, 2007; MPRJ, 2013; SAP Portugal 2014), tais quais:

Logística: Compras, contratos, patrimônio, almoxarifado, transporte, viagens;

Financeira e Orçamentária: Orçamento, finanças e contabilidade pública; 
Gestão de recursos humanos: Folha de pagamento, saúde, licenças, férias;

Gestão de obras e manutenção predial: Recuperação da capacidade funcional da edificação e de suas partes constituintes; planejamento e execução dos requisitos de segurança predial, da estética, das expansões, gerenciamento de insumos das obras, entre outras;

Gestão da Dívida e Receita Tributária: Manutenção de contas e registros, processamento de declarações e pagamentos, correspondência, faturamento, auditorias e conformidade, bem como apoio ao cidadão e gestão de contestações;

Gestão de Subsistemas de Proteção Social: Gestão de casos específicos e serviços a cidadãos;

Soluções para e-government: Aumento da eficácia e transparência de processos de forma a corresponder às expectativas dos cidadãos e outros destinatários dos serviços governamentais;

Serviços de Proteção ao Cidadão: Consolidação de dados, compartilhamento de informações e verificação dos recursos estão disponíveis para suportar processos críticos de segurança;

Relatórios gerenciais: Emissão de relatórios diversos para a tomada de decisão.

Ademais, enfatiza-se a importância de um ERP governamental ser totalmente customizável, sendo capaz de atender as especificidades de cada órgão público. Além disso, é essencial que no contrato estejam previstos os seguintes elementos: customização; instalação, configuração do ambiente tecnológico; integração com os sistemas estruturantes; migração de dados e implantação assistida; garantias; manutenção corretiva; suporte técnico; evolução tecnológica; atualização do software em virtude de mudanças na legislação pertinentes; treinamento dos usuários; adição de novas funcionalidades; alteração das já existentes e automação de processos (manutenção evolutiva), entre outros (MPRJ, 2013).

Entretanto, antes da implantação de sistemas integrados, é necessário desenvolver uma visão de alto nível baseada nos processos de negócios, considerando o ERP como tecnologia de suporte. O Acórdão no ${ }^{2}$.523/2012 do TCU trata dos sistemas informatizados de gestão das empresas estatais e estabelece diretrizes a serem observadas nas contratações. O mesmo documento ressalta que basicamente $75 \%$ do mercado é controlado por três fornecedores: SAP, Oracle e TOTVS (TCU, 2012b).

Tricate (2014) ainda complementa afirmando que as soluções ERP oferecem serviços de suporte (corretivo) e novas versões (evolutivo) a um custo previsível e mais baixo quando comparado ao custo de manter sistemas desenvolvidos internamente. Destaca-se que uma das características é o alto grau de integração entre as suas diversas funções, o que permite que uma simples transação de reserva de material ou o apontamento de um serviço seja compartilhado por todas as funções interessadas, sejam elas de cunho logístico ou financeiro, registrando-se a intervenção de todos os usuários do sistema. Assim, eliminam-se etapas de retrabalho ou reanálise de forma a garantir a qualidade e confiabilidade das informações, o que é requisito para a transparência nas informações no setor público. A próxima seção destina-se a apresentar o método e técnicas utilizados na pesquisa. 


\section{Método e técnicas da pesquisa}

A presente pesquisa pode ser classificada do ponto de vista de sua natureza como aplicada; do ponto de vista de seus objetivos, é considerada descritiva; quanto à forma de abordagem, como quali-quantitativa; e no que se refere ao procedimento técnico, utilizou o estudo de caso (Silva e Menezes, 2005).

$\mathrm{O}$ estudo de caso foi realizado junto à Secretaria Executiva do MJ, tendo como principal objeto o Projeto Ciclo. É importante ressaltar que em um primeiro momento da pesquisa realizou-se uma revisão da literatura sobre o tema, na qual foram examinados artigos focados na implementação de TI e sistemas ERP, a fim de embasar a construção do instrumento de coleta de dados (questionário).

Para a coleta de dados foram utilizados três tipos de instrumento de pesquisa, os quais foram: i) questionário de pesquisa; ii) análise documental; e iii) observação direta. De acordo com Yin (2001), a combinação de dois ou mais instrumentos de pesquisa, denominada "triangulação", proporciona maior confiabilidade nas constatações obtidas com o estudo de caso, pois as informações obtidas podem ser complementadas e validadas em mais de uma fonte.

O questionário foi composto por 10 perguntas fechadas, baseadas no objetivo da pesquisa, nos aspectos teóricos a respeito de sistemas ERP e também, mais especificamente, sobre o Projeto Ciclo/MJ. As variáveis envolvidas no questionário foram: a) percepção do ERP como ferramenta para tomada de decisão; b) conhecimento dos usuários sobre o Projeto Ciclo/MJ; c) importância do papel das pessoas na implementação do ERP governamental; d) importância do papel da TI na tomada de decisões gerenciais; e) usabilidade do sistema ERP; f) resistência e fuga de utilização do ERP para obter informações; e g) impacto do uso do ERP na rotina de trabalho. As respostas foram baseadas em uma escala do tipo Likert variando de 1 a 10, sendo 1 considerado o menos importante e 10 o mais importante. As perguntas podem ser visualizadas no quadro 1 .

\section{Quadro 1}

\section{Perguntas do questionário de pesquisa}

\begin{tabular}{|l|l|}
\hline № & Pergunta \\
\hline 1. & Você considera o Projeto Ciclo/MJ uma ferramenta de apoio à tomada de decisão gerencial? \\
\hline 2. & Você conhece a relação de cooperação entre o Ministério da Justiça e a Universidade Federal do Rio Grande do Norte? \\
\hline 3. & $\begin{array}{l}\text { Você considera importante o papel das pessoas na condução dos sistemas de gerenciamento integrados para facilitar o } \\
\text { uso de informações? }\end{array}$ \\
\hline 4. & $\begin{array}{l}\text { Você considera importante o papel da tecnologia de informação no desenvolvimento de sistemas de gerenciamento } \\
\text { integrados para facilitar o uso de informações? }\end{array}$ \\
\hline 5. & Você considera o Projeto Ciclo/MJ um sistema de informação gerencial de fácil navegação? \\
\hline 6. & Você utiliza planilhas ou outros bancos de dados para visualizar informações referentes a Contratos? \\
\hline 7. & Você utiliza planilhas ou outros bancos de dados para visualizar informações referentes a Convênios? \\
\hline 8. & Você utiliza planilhas ou outros bancos de dados para visualizar informações referentes a Almoxarifado e Patrimônio? \\
\hline 9. & Você utiliza planilhas ou outros bancos de dados para visualizar informações referentes a Gestão de Pessoas? \\
\hline 10. & Você acredita que a inserção de dados nos sistemas do Projeto Ciclo/MJ interfere na sua rotina de trabalho? \\
\hline
\end{tabular}

Fonte: Dados da pesquisa (2013). 
A amostragem caracteriza-se como não probabilística e por acessibilidade; a escolha dos respondentes foi baseada no critério de representatividade, os quais foram os gerentes do Projeto Ciclo/MJ, que totalizam 25 pessoas, sendo os principais envolvidos no processo de implementação. Foram distribuídos 20 questionários aos gerentes do Projeto Ciclo/MJ que concordaram em participar da pesquisa e obteve-se um retorno de 100\%, dos quais 18 foram considerados válidos e dois descartados por não terem sido preenchidos completamente. Destaca-se que surgiram limitações de pesquisa, como falta de preenchimento de todos os dados, limitação de tempo dos respondentes para a realização de entrevistas e negativa de cinco gerentes em participar.

Para complementar a coleta de dados, foi realizada a análise documental, que se constituiu do levantamento de dados em documentos internos do MJ e também disponíveis ao público. Além disso, foi realizada a observação direta dos processos internos, tendo em vista que um dos pesquisadores trabalha no órgão sob estudo e teve condições de constatar alguns fatos não informados no questionário de pesquisa, a qual foi utilizada para coletar informações sobre os ambientes organizacionais (internos e externos), os contextos das cooperações técnicas e a amplitude das redes de cooperação. Posteriormente à etapa da coleta de dados, os dados foram tabulados, sendo calculada sua frequência, e tornou-se possível que os resultados fossem analisados criticamente com base na técnica de análise categorial temática proposta por Bardin (1977), o que possibilitou a discussão, a elaboração das considerações finais e sugestões para estudos futuros.

\section{Apresentação e análise dos resultados}

Os resultados da pesquisa são apresentados em categorias definidas a priori, com base na técnica de análise categorial temática. Ressalta-se que os resultados das categorias 7.1 e 7.2 são provenientes de análise documental e observação direta, enquanto as categorias 7.3 a 7.6 apresentam os resultados obtidos por meio do questionário de pesquisa, que teve o intuito de analisar a percepção dos gestores quanto ao Projeto Ciclo (usuários do ERP governamental) no âmbito do TJ e da observação direta.

\subsection{Caracterização do Projeto Ciclo/MJ}

No ano de 2008, a Secretaria Executiva do Ministério da Justiça realizou a revisão do seu planejamento estratégico com o uso do Balanced Scorecard (BSC) proposto por Kaplan e Norton (1992). Para isso foi construído um mapa estratégico, no qual dois objetivos estratégicos se destacavam: i) promover o uso integrado de informações; e ii) gerar informações confiáveis com rapidez e segurança (Barreto e Dostler, 2009). De acordo com Lima e colaboradores (2010), essa mudança era emergente e urgente, pois a pressão das demandas sociais nas áreas de segurança pública, defesa de direitos e garantia da cidadania já não comportava o modelo burocrático de gestão estratégica. A figura 1 apresenta o mapa estratégico gerado nesse processo. 


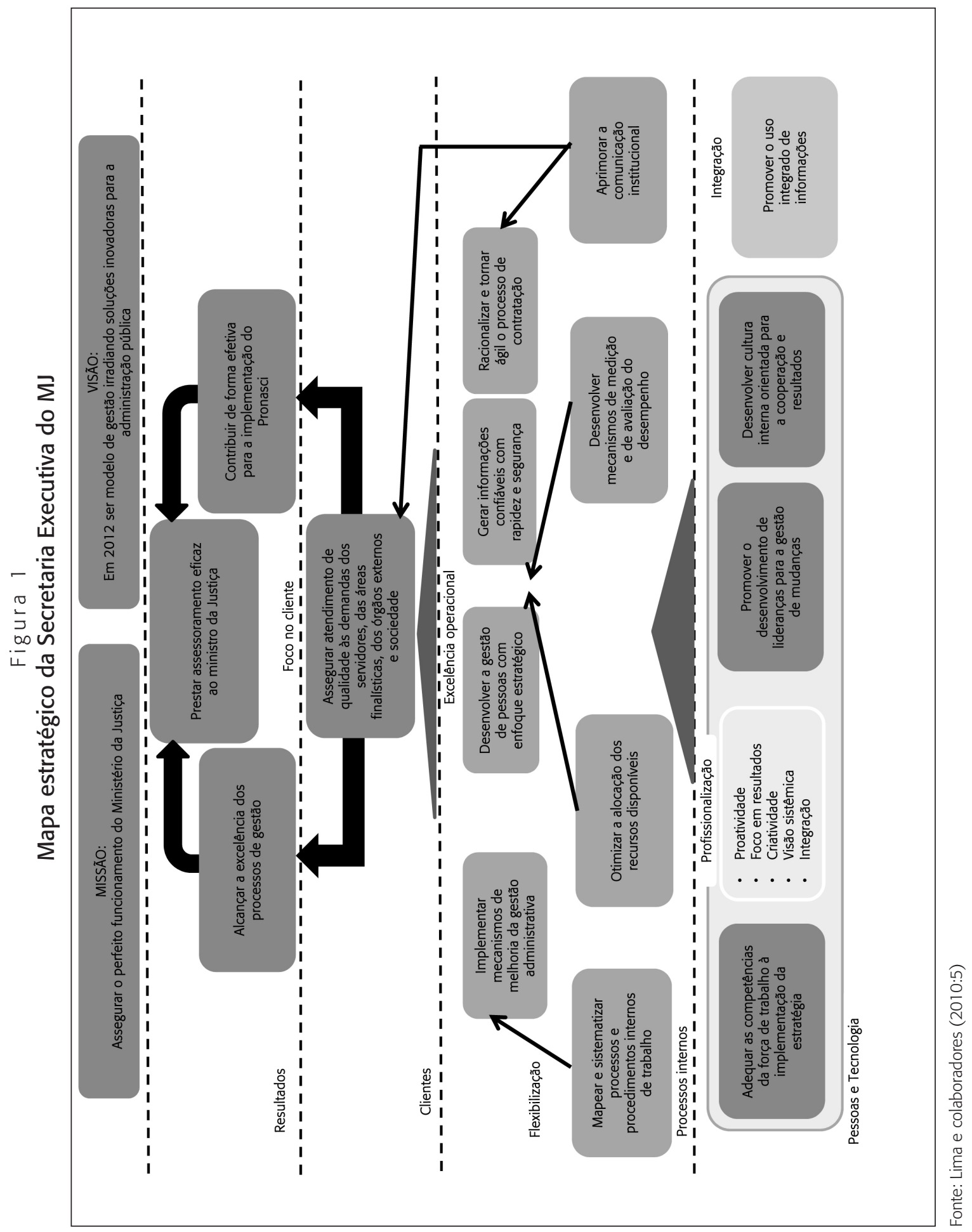


Conforme pode ser percebido na figura 1, o Projeto Ciclo/MJ passou a ser considerado o instrumento capaz de fornecer aos gestores o acesso às informações necessárias aos processos de tomada de decisão no MJ de forma ágil, eficaz, eficiente e efetiva (Lima et al., 2010).

Em 2009, o MJ, com o intuito de desenvolver sistemas informatizados de controle administrativo, adaptados à realidade governamental na esfera federal, firmou parceria, via acordo de cooperação técnica, com a UFRN, para a modernização da gestão e a implantação de sistemas de gestão administrativa e de pessoas, em vez de optar pela contratação de uma empresa privada para o desenvolvimento do sistema e seus módulos.

O referido projeto tem na construção do conhecimento por meio de redes colaborativas o seu ponto forte. Com isso, cada participante desenvolve módulos específicos nos sistemas de gestão administrativa e de pessoas e a UFRN identifica cada realidade peculiar dos parceiros e generaliza os módulos do sistema a todos os integrantes da rede de cooperação. Esse sistema de gestão administrativa e de pessoas pode ser entendido como um ERP governamental, pois possui módulos que abrangem a operacionalização dos processos realizados por empresas do serviço público (Brasil, 2009).

O Projeto Ciclo/MJ tem o objetivo de agregar informações orçamentárias, financeiras, gerenciais e de planejamento de modo a oferecer aos destinatários, tais como dirigentes, gerentes de projetos e fiscais de contratos, informações precisas sobre os processos administrativos existentes nas organizações, facilitando assim o controle gerencial das atividades do MJ e configurando-se como um ERP governamental (Brasil, 2010).

Dessa maneira, a UFRN disponibiliza ao Ministério da Justiça dois produtos: i) o Sistema Integrado de Patrimônio, Administração e Contratos (Sipac); e ii) o Sistema Integrado de Recursos Humanos (SIGRH). Esses software-livres criados pela diretoria de sistemas da UFRN são disponibilizados à coordenação geral TI do MJ, a qual os customiza de acordo com as necessidades existentes (Brasil, 2009).

Conforme Lima e colaboradores (2010), no decorrer do ano de 2009, aproximadamente 400 gestores e usuários participaram, durante 3.300 horas, de atividades presenciais ou de videoconferências, com o objetivo de aprofundar-se sobre as funcionalidades do Sipac, SIGPRH e Sigaa da UFRN. Já no que se refere à integração com os sistemas estruturantes, a rede contou com a participação mais efetiva do MJ e da UFRN para interagir com o MPO e Serpro na definição de estratégias para a implementação de interoperações via WebServices, XML ou extratores de dados já disponíveis.

O produto Sipac oferece diversas funcionalidades, também chamadas de módulos, para o controle da gestão corporativa. Em apenas um sistema integrado é possível efetuar requisições de materiais e serviços, cadastrar suprimentos de fundos, requisitar diárias e passagens e outras funcionalidades. Atualmente são 20 módulos desenvolvidos pela UFRN para o Sipac. Cada módulo dos sistemas podem ser, ou não, instalado. Depende da conveniência de cada instituição (Brasil, 2010).

Suas informações utilizam bancos de dados internos e realizam a interoperação com os sistemas estruturantes do governo (Siafi, Siape, Sidor, Sigplan, dentre outros). Porém, atualmente a extração não é automática, muitas vezes o trabalho é manual, sobrecarregando a equipe de TI do MJ. Esse fato dificulta a interoperabilidade no âmbito do MJ (Brasil, 2010). 
O SIGRH funciona de maneira análoga. Porém, os módulos, ao invés de gerenciar bens e serviços, facilitam o trabalho dos gestores de recursos humanos. Com ele é possível alterar férias, efetuar cálculos de tempo de serviço, controlar a frequência dos servidores e colaboradores, dentre inúmeros outros módulos. Ao todo, a UFRN desenvolve 25 módulos do SIGRH (Brasil, 2010).

Outra meta do Projeto Ciclo/MJ é a integração desses sistemas administrativos, desenvolvidos em conjunto com a UFRN, com os principais sistemas estruturantes do governo federal: Sistema Integrado de Administração Financeira (Siafi), Sistema Integrado de Administração de Serviços Gerais (Siasg), Serviço de Informações Gerenciais e de Planejamento (Sigplan) e Sistema Integrado de Orçamento e Planejamento (Siop). Em suma, busca-se a informação nos sistemas estruturantes (base de dados externa) e alimenta-se com informações dos sistemas Sipac e SIGRH (base de dados interna). Essa divisão em bases de dados interna e externa tem por objetivo diminuir o retrabalho de inserção de dados (Brasil, 2009).

O ERP governamental utiliza os sistemas estruturantes e os customiza, integrando-os em uma plataforma única, a fim de possibilitar a ligação de todos os processos governamentais. Essa customização é necessária devido à necessidade de abranger as informações relativas à legislação já existentes nos sistemas estruturantes.

O Projeto Ciclo/MJ foi estruturado de forma análoga a um sistema ERP, também chamado de sistema integrado de gestão empresarial, já que incorpora funcionalidades de vários sistemas estruturantes em um único programa. Para Mitchell (2006), cada vez mais as organizações buscam soluções de TI inovadoras, geralmente adotando uma estratégia de baixo custo de personificação e invenção de produtos. Para o autor, esse tipo de atuação recebe o nome de personificação em massa, já que busca a estabilidade dos processos de TI e, ao mesmo tempo, que eles sejam flexíveis, genéricos e principalmente modulares.

Além disso, o Projeto Ciclo/MJ, por ser um sistema integrado, facilita a transparência da informação. A tendência é facilitar o acesso do cidadão a qualquer dado público, desde que não protegido por sigilo. Assim, dados relativos a contratos, convênios e de pessoal são facilmente pesquisados, contribuindo para o controle social (Brasil, 2009).

Segundo Lima e colaboradores (2010), a arquitetura do sistema adotada é a Java Enterprise Edition (JEE). Para o autor, essa arquitetura facilita a definição de padrões de codificação, visualização e navegação em sistemas web. No âmbito do MJ, o Projeto Ciclo/MJ adota os sistemas coorporativos consolidados da UFRN, Sipac e SIGRH, ambos em fase de implantação dos módulos.

\subsection{Rede de cooperação técnica no Projeto Ciclo/MJ}

Malmegrin (2011) ressalta que, apesar de não se classificar como redes públicas de cooperação local municipal, o escopo de atuação do projeto é muito semelhante a qualquer forma de rede de cooperação, pois possui na construção em rede colaborativa de informações sua maior fonte de conhecimento. A autora também sugere a ação orientada para a lógica coletiva como um fator de sucesso para o funcionamento das redes de cooperação. 
Nesse contexto, tem-se a importância da rede de cooperação técnica existente entre o MJ e a rede Ciclo. A relação de cooperação entre todos os atores faz surgir as atualizações necessárias aos sistemas desenvolvidos pela UFRN. Assim, cada ator desenvolve da melhor forma possível, com parâmetros de controle e evolução de atualizações, as melhorias dos sistemas ERP, tornando os produtos desenvolvidos pela UFRN, de fato, realidade entre os cooperados. Caso haja interesse de desenvolvimento de um módulo chamado, por exemplo, auditoria no produto Sipac, pode-se solicitar, por meio da Cooperação Técnica, à Controladoria Geral da União (CGU) (por ser integrante da rede de Cooperação), o desenvolvimento em conjunto com a UFRN desse módulo (Brasil, 2009). Dessa maneira, utiliza-se conhecimento técnico da CGU para aprimorar os mecanismos de controle, e a UFRN incrementa o módulo com seu conhecimento em fabricação de sistemas de informação. A figura 2 apresenta os relacionamentos entre as instituições envolvidas.

Figura 2

Rede de relacionamentos na Cooperação Ciclo

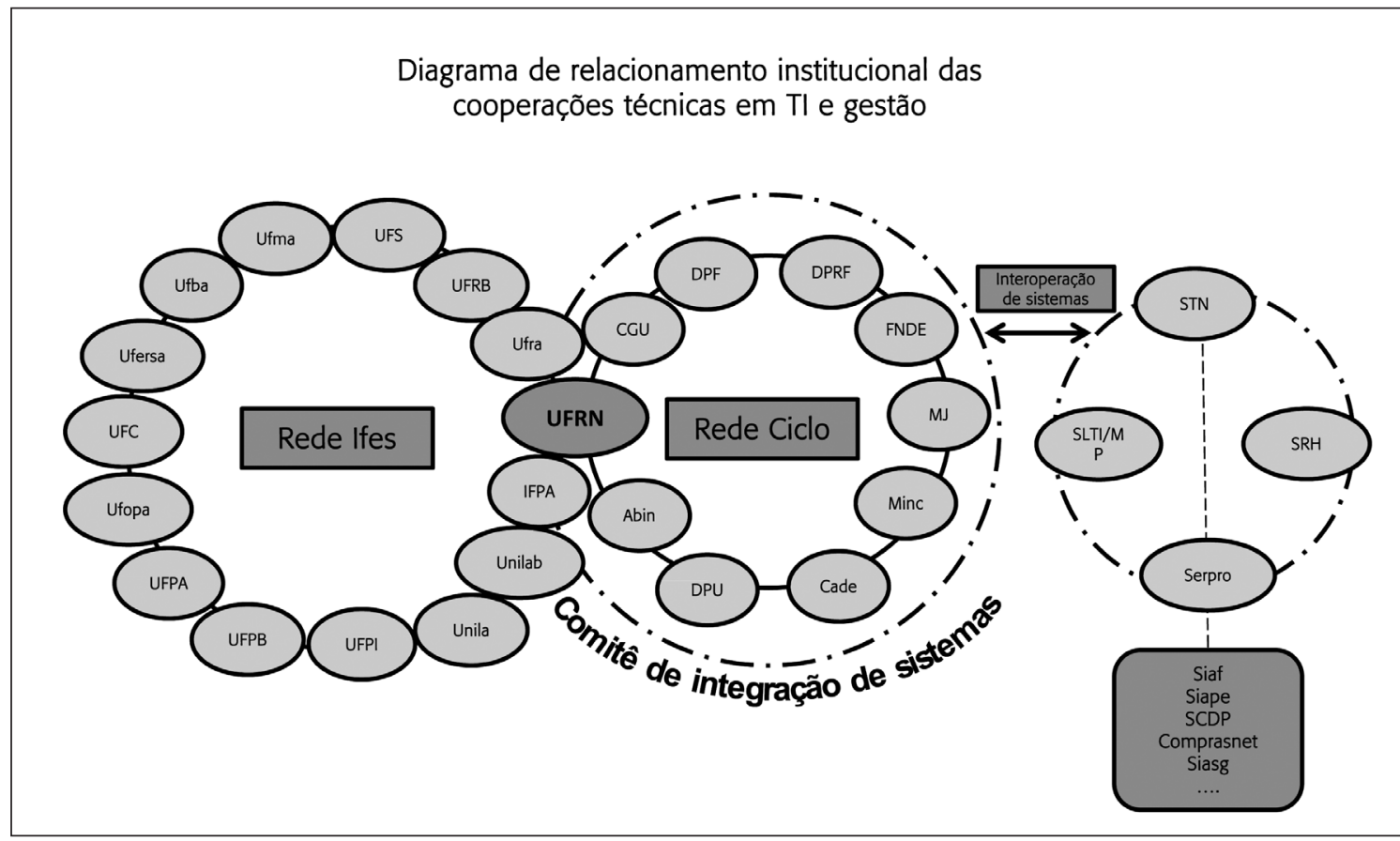

Fonte: Brasil (2009).

Conforme explicitado na figura 2, a rede Ifes engloba as instituições federais de ensino superior que efetuaram acordo de cooperação técnica para usufruto dos produtos desenvolvidos pela UFRN (Sipac e SIGRH). A rede Ciclo contempla órgãos da administração direta federal que efetuaram, também, acordos de cooperação técnica para usufruto dos dois siste- 
mas. Ambas as redes buscam a interoperação dos sistemas estruturantes e cada ator, individualmente, implementa as atualizações dentro da sua realidade, considerando que a UFRN é a provedora dos produtos do Projeto Ciclo/MJ e o comitê de integração de sistemas promove o intercâmbio entre os envolvidos. Segundo Lima e colaboradores (2010:10), a rede Ifes e a rede Ciclo, juntas, "apresentam demandas estruturadas para a construção de componentes e ferramentas de interoperabilidade e integração com os sistemas estruturantes".

Malmegrin (2011) acrescenta que a governança numa rede de cooperação facilita a organização dos trabalhos, além de identificar a autonomia de cada ente participante. Além disso, Lima e colaboradores (2010:10) destacam o espírito colaborativo das redes de cooperação: "cada instituição faz parte desta mudança, sem imposição de protagonistas, mas sim por reconhecimento coletivo de potencialidades para o alcance de objetivos comuns". Essas visões criam o ambiente facilitador no processo de desenvolvimento das redes de cooperação.

O fluxo de informação no âmbito do Projeto Ciclo/MJ é sempre retroalimentado por todos os atores envolvidos. Desde o planejamento até o desenvolvimento de atividades gerenciais, trabalha-se de modo intenso a informação. Os fiscais de contratos são responsáveis pelas informações iniciais, já que eles são as pessoas da base para a inserção de dados (Brasil, 2009).

Apesar dos inúmeros benefícios dos sistemas ERP, é muito comum encontrar dificuldades para colocá-los em prática conforme ressaltado pelos autores citados, as quais podem ser de aspecto tecnológico, como também de pessoas. No primeiro caso, a evolução tecnológica praticamente inviabiliza a criação de sistemas sem constantes atividades de suporte operacional. No segundo caso, as pessoas, apesar de serem o capital intelectual da organização, podem sair a qualquer momento e, nesse caso, a rotatividade de pessoal interfere diretamente na condução do processo de implementação (Brasil, 2009).

No caso das integrações com os sistemas estruturantes do governo federal (Siafi, Siape e outros), Lima e colaboradores (2010) destacam o importante papel desenvolvido pela Secretaria de Logística e Tecnologia da Informação do Ministério do Planejamento (SLTI/ MP). Para o autor, essas integrações aperfeiçoam os produtos desenvolvidos pela UFRN e promovem a confiabilidade dos dados, impulsionando as melhorias colaborativas entre todos os atores da rede Ciclo. As próximas seções (7.3 a 7.6) abrangem os resultados levantados por meio do questionário de pesquisa, que objetivou analisar a percepção dos usuários do ERP governamental no âmbito do MJ, quanto ao Projeto Ciclo.

\subsection{Percepção dos usuários quanto ao ERP governamental como ferramenta de apoio à tomada de decisões}

A primeira questão do instrumento de pesquisa procurou verificar se os respondentes consideram a implementação do sistema ERP governamental por meio do Projeto Ciclo/MJ como uma ferramenta de apoio à tomada de decisão gerencial. Com base nos resultados, observouse que $80 \%$ dos respondentes acreditam que o Projeto Ciclo/MJ é uma ferramenta de apoio à tomada de decisão muito importante, e os demais a consideram de média a baixa impor- 
tância. Esse índice elevado de reconhecimento do ERP governamental ao apoio à tomada de decisões é corroborado por Helmy, Mohamed e Mosaad (2012), que afirmam que integrar todas as informações departamentais e funcionais em um único sistema facilita a gestão da empresa e ainda torna possível que decisões relativas a: finanças, inventário, compras, gestão de pedidos, produção, entre outras, sejam tomadas de forma mais adequada e confiável.

\subsection{Percepção quanto ao nível de conhecimento do Projeto Ciclo pelos usuários}

Com o intuito de avaliar o nível de conhecimento dos respondentes em relação ao Projeto Ciclo, tendo como base a rede de cooperação instituída para tal, constatou-se que todos os respondentes afirmaram conhecer a relação existente entre o MJ e a UFRN, conforme respostas obtidas na questão 2. Complementando essa questão com a observação direta realizada, verificou-se que esse fato se deve à ampla divulgação do Projeto Ciclo no âmbito do MJ e ao grau de comprometimento da alta direção para o atingimento dos objetivos do referido projeto. $\mathrm{O}$ alto índice de respostas afirmativas na questão 2 demonstrou que o processo colaborativo entre o MJ e a UFRN apresenta resultados satisfatórios. Esse fato corrobora o exposto por Tripadalli, Fernandes e Machado (2011), que afirmam que a implantação de projetos de integração de informações requer planejamento e infraestrutura de TICs adequados, equipe bem treinada, ampla divulgação ao quadro de funcionários envolvidos e atos do governo que inspirem confiança nos usuários.

\subsection{Percepção quanto ao papel das pessoas e da tecnologia da informação no processo de implementação}

Conforme dados da questão 3, constatou-se o reconhecimento dos usuários de que as pessoas possuem papel decisivo na condução dos sistemas de gerenciamento integrados: 97,5\% dos respondentes consideram que, para o gerenciamento integrado de sistemas informacionais, o envolvimento pessoal é decisivo. Segundo Mintzberg e colaboradores (2006), o comprometimento pessoal é importantíssimo, já que são as pessoas que fazem as parcerias darem certo. Esse alto índice de respostas confirma o afirmado por DeLone e McLean (1992), Laudon e Laudon (2004), Medeiros Jr., Perez e Shimizu (2009), Brodbeck e colaboradores (2009) e Biancolino e colaboradores (2011), os quais concordam que dentre os fatores diretamente responsáveis pelo sucesso ou fracasso da implementação dos sistemas ERP estão o papel e envolvimento dos usuários no processo, tendo em vista que os grupos sociais envolvidos interferem em todas as etapas de implementação. Biancolino e colaboradores (2011) ainda acrescentam que, considerando que os sistemas ERP normalmente são precursores de contínuas mudanças na gestão dos processos de negócios das empresas, as capacidades ou competências organizacionais estão diretamente associadas à criação de valor para a organização.

Os usuários também consideraram como muito importante o papel da TI no desenvolvimento de sistemas de gerenciamento integrados para facilitar o uso de informações: 85\% dos 
respondentes creem que a TI facilita o uso de informações, o que corrobora a afirmação de Mintzberg e colaboradores (2006), os quais afirmam que a tecnologia promove o desenvolvimento de inúmeros produtos; dentre eles, têm-se os bancos de dados como fundamentais para a melhor implementação da estratégia competitiva. Ademais, essa percepção dos respondentes confirma o exposto por Villas, Fonseca e Macedo-Soares (2006) e Tridapalli, Fernandes e Machado (2011), que afirmam que as empresas podem obter vantagens competitivas com o uso de TI.

\subsection{Percepção quanto à usabilidade e ao impacto nas rotinas de trabalho do ERP governamental}

No que se refere à questão 5 (Você considera o Projeto Ciclo/MJ um sistema de informação gerencial de fácil navegação?), obteve-se $100 \%$ de respostas favoráveis. Dessa maneira, observase que a arquitetura informacional do projeto e suas telas de navegação não comprometem, nem confundem o usuário do sistema. Fato apontado por Clark, Jones e Zmud (2006) e Li, Chen e Huang (2006) como muito importantes para o sucesso do processo, tendo em vista que os usuários do sistema, quando não satisfeitos com a usabilidade do sistema, podem boicotar seu uso e sua efetiva implementação.

As questões 6, 7, 8 e 9 demonstram o nível de utilização por parte dos usuários de outros sistemas que não o ERP governamental, tendo em vista verificar a aceitabilidade dos módulos implementados, o que pode identificar se há resistência e fuga na utilização do ERP.

Mais especificamente relacionado com a questão 6 (Você utiliza planilhas ou outros bancos de dados para visualizar informações referentes a Contratos?), obteve-se baixo índice de utilização por ser o único módulo implantado no MJ. Apenas 30\% dos respondentes afirmaram consultar planilhas para obter alguma informação complementar sobre contratos. Tal fato representa a aceitação pelos usuários do sistema ERP governamental implementado pelo Projeto Ciclo/MJ quanto ao módulo de contratos, já que o banco de dados atende ao que ele se propõe, ou seja, obter informações gerenciais de fácil acesso.

Fato oposto ocorrido com as questões de números 7 e 9, as quais, respectivamente, alcançaram 90\% e 95\% de utilização de planilhas para consultar dados relativos a convênios e pessoas. Esses resultados foram justificados posteriormente, após pesquisa documental, pois se constatou que os módulos ainda não estão implementados efetivamente, o que dificulta a avaliação por parte dos usuários. Ressalvada a questão número 8, na qual 65\% dos entrevistados afirmaram utilizar planilhas para consultar dados relativos a almoxarifado e patrimônio, o que se justifica pelo módulo estar em fase de homologação. Dessa maneira, sustenta-se o argumento que a fase de testes do sistema compromete a análise mais profunda dos usuários.

A questão de número 10 (Você acredita que a inserção de dados nos sistemas do Ciclo-MJ interfere na sua rotina de trabalho?) obteve média 6,75. Tal fato demostra que, independentemente da nova metodologia de trabalho, os servidores do MJ compreendem a necessidade do sistema de informações gerenciais, e tal fato não cria o chamado retrabalho, fato bastante 
prejudicial ao serviço público e ao desempenho do empregado. DeLone e McLean (1992) apontam a qualidade da informação e do sistema, o grau de uso, a satisfação do usuário e o impacto no trabalho individual como principais fatores de sucesso na implementação de tais sistemas, o que permite que a mudança de procedimentos ocorra sem maiores problemas.

\section{Considerações finais}

Com as novas tendências de escassez de recursos financeiros, crescimento das expectativas dos cidadãos, necessidade de maior eficácia e transparência na administração pública, as organizações públicas são impelidas a repensar e reorganizar seus processos internos. Uma das tendências claramente percebidas é a adoção por organizações públicas de sistemas integrados de gestão, como o ERP, o qual pode ser desenvolvido internamente, por empresas especializadas ou por meio de cooperação técnica.

Nesse contexto, destaca-se o Projeto Ciclo/MJ, o qual pode ser considerado inovador na esfera pública por envolver uma rede de cooperação técnica que integrou diversas instituições com o intuito de desenvolver módulos de um sistema ERP governamental. Com o decorrer dos processos da implementação do ERP governamental no âmbito da Secretaria Executiva do MJ, surge a necessidade de identificar se o acordo de cooperação técnica surtiu os efeitos a que se destinou, de acordo com a percepção dos usuários vinculados ao Projeto Ciclo/MJ. Além disso, destaca-se a importância de se descrever como ocorreu tal processo a fim de contribuir com as organizações públicas que tenham interesse em tal alternativa de implantação do sistema.

Ressalta-se que, apesar de existirem um arcabouço teórico e pesquisas já consolidadas acerca dos sistemas ERP na área privada, ainda se carece de pesquisas que tratem da área pública, pois somente nos últimos anos o sistema ERP passou a ser implementado em organizações governamentais no Brasil. Devido às especificidades dessas organizações, principalmente no que se refere a recursos humanos, atividades específicas e processos vinculados à legislação, além da necessidade de prestação de contas à sociedade, a pesquisa é pertinente e pode servir como base para estudos futuros sobre a implementação do ERP na área pública.

Pode-se afirmar, inicialmente, que se percebeu uma intensa relação entre pessoas e tecnologia e que o uso coordenado de conhecimentos das áreas de TI e gestão de pessoas, quando bem gerenciados, facilita a promoção da implementação de sistemas integrados de gestão. Observou-se também que o acordo de cooperação técnica com a UFRN constitui-se em uma estratégia relevante para o $\mathrm{MJ}$, a qual não deixa de ser de complexa execução, considerando que desde 2009 os integrantes da rede buscam a integração dos módulos pactuados no acordo de cooperação.

Ademais, foi possível notar que o gerenciamento de sistemas integrados é um processo complexo que demanda grande capacidade de articulação e gerenciamento de equipes. A construção e o desenvolvimento de qualquer organização dependem do trabalho das pessoas. Suas tarefas, por mais simples que pareçam, estão arranjadas de tal forma que a ausência de um processo desencadeia falhas em processos mais complexos. Dessa forma, pressupõe-se que 
cada vez mais o envolvimento das pessoas em projetos de TI, principalmente no âmbito de sistemas de gestão integrada, é fator decisivo para o sucesso do projeto.

Constatou-se que os usuários do ERP governamental conhecem a importância dos sistemas integrados de gestão, principalmente como apoio à tomada de decisão. Além disso, verificou-se que os usuários estão cientes do papel que desempenham no processo de implementação e que a TI é fundamental para se obter melhoria nos processos executados. Existem alguns módulos que não possuem ainda ampla utilização, tendo em vista não estarem completamente homologados e implementados: no entanto, reconhece-se que o sistema é de fácil navegação e importante para as rotinas de trabalho. Cabe ressaltar que a resistência à mudança atrapalha a implementação de sistemas de informação. Visando sanar essa dificuldade e realçar a importância da mudança de cultura organizacional, cada vez mais o escritório de projetos central do MJ tem investido em ações de conscientização sobre o uso correto de sistemas de informações. Por meio de observação direta percebeu-se que com essas ações pontuais, aos poucos, a cultura da utilização do sistema vem sendo disseminada no MJ.

Por meio desta pesquisa foi possível constatar que o Projeto Ciclo/MJ busca a melhoria nos processos gerenciais e tem cumprido sua missão de desenvolver sistemas informatizados de controle administrativo, adaptados à realidade governamental, constituindo-se as redes de cooperação técnica em uma alternativa válida para o desenvolvimento de sistemas integrados de gestão, como o ERP. Ademais, percebe-se que os usuários a reconhecem como uma ferramenta viável de apoio à tomada de decisão gerencial.

No que se refere às limitações do estudo, ressalta-se que as considerações elencadas neste estudo de caso representam a visão do ambiente dos servidores e colaboradores de uma pequena parcela de servidores do MJ, cujos respondentes foram os gestores envolvidos no projeto. Sugere-se que em estudos futuros seja verificada a percepção de outros níveis de atuação, bem como de outros fatores organizacionais não abordados neste estudo. Não foram analisados também aspectos relacionados com a comparação da eficácia da realização dos processos internos antes e depois da implementação, bem como aspectos voltados ao montante de recursos dispendidos nesse processo.

Por se tratar da primeira pesquisa com este foco no âmbito do Projeto Ciclo/MJ, sugerese a realização de novos estudos considerando outros fatores no processo de implementação do projeto. Além disso, tendo em conta a abordagem incipiente do tema ERP governamental na literatura, recomenda-se o estudo desse tema em outras organizações públicas. Bem como sugere-se a análise de processos de implementação de ERPs governamentais desenvolvidos internamente e por empresas especializadas, comparando-se com o desenvolvimento por meio de redes de cooperação técnica, a fim de analisar as implicações das alternativas existentes na esfera pública.

\section{Referências}

ABREU, Ana Claudia D. et al. O uso de tecnologias de informação na administração pública: o caso do Procidadão. In: CONGRESSO NACIONAL DE EXCELÊNCIA EM GESTÃO — CNEG, VIII, 2012, Rio 
de Janeiro. Anais... (Online), p. 1-12. Disponível em: <www.excelenciaemgestao.org/pt/edicoesanteriores/viii-cneg/anais-do-viii-cneg.aspx>. Acesso em: 3 jul. 2014.

ALBARDIN, Alberto L.; ALBARDIN, Rosa Maria M. Benefícios do uso de tecnologia de informação para o desempenho empresarial. Rev. Adm. Pública, Rio de Janeiro, v. 42, n. 2, p. 275-302, mar./ abr. 2008.

AROZO, Rodrigo. Softwares de supply chain management: definições, principais funcionalidades e implantação por empresas brasileiras. In: FIGUEIREDO, Kleber F.; FLEURY, Paulo F.; WANKE, Peter. Logística e gerenciamento da cadeia de suprimentos: planejamento do fluxo de produtos e dos recursos. Atlas: São Paulo, 2003.

BARDIN, Laurence. Análise de conteúdo. Lisboa: Edições 70, 1977.

BARRETO, Luiz Paulo T. F.; DOSTLER, Peter M. Gestão estratégica na administração pública. In: WEST, Marcos Antonio M. Gestão estratégica no Ministério da Justiça 2009. Brasília: Secretaria Executiva/MJ, 2009. p. 12-31.

BHARADWAJ, Anandhi S. A resource-based perspective on information technology capability and firm performance: an empirical investigation. MIS Quarterly, v. 24, n. 1, p. 169-196, 2000.

BIANCOLINO, Cesar Augusto et al. A gestão de TI e o valor de uso dos ERP's em sua perspectiva de pós implementação. Revista Eletrônica de Ciência Administrativa, Campo Largo, v. 10, n. 2, p. 5-19, jul./dez. 2011.

BRASIL. Acordo de Cooperação Técnica n 001/2009. Disponível em: <www.mj.gov.br/> . Acesso em: 11 maio 2012.

BRASIL. Ministério do Planejamento Orçamento e Gestão. Panorama da interoperabilidade no Brasil. Brasília: Secretaria de Logística e Tecnologia da Informação, 2010.

BRODBECK, Henrique J. et al. Configuração de um processo de seleção, aquisição e implementação de ERP considerando os grupos sociais envolvidos. Revista Eletrônica de Sistemas de Informação, v. 9, n. 1, p. 1-30, 2009.

CARVALHO, Rodrigo B. et al. Fatores-chave na implantação de ERPs: estudo de um caso problemático em uma média indústria. Revista Eletrônica de Sistemas de Informação, v. 8, n. 2, p. 1-19, 2009.

CAVALCANTI, Marly. Gestão estratégica de negócios: evolução, cenários, diagnóstico e ação. São Paulo: Pioneira Thomson Learning, 2001.

CLARK JR., Thomas D.; JONES, Mary C.; ZMUD, Robert W. Post adoptive ERP use behaviors: a dynamic conceptualization. In: The 27th International Conference of the System Dynamics Society Albuquerque, 27., 2009, Novo México. Proceedings of the 27th International Conference of the System Dynamics Society Albuquerque. Novo México, 2009.

COLANGELO FILHO, Lucio. Implantação de sistemas ERP: um enfoque de longo prazo. São Paulo: Atlas, 2001.

CORRÊA, Henrique L.; GIANESI, Irineu G. N.; CAON, Mauro. Planejamento, programação e controle da produção. 4. ed. São Paulo: Atlas, 2001. 
DAFT, Richard L. Organizações: teoria e projetos. São Paulo: Cengage Learning, 2008.

DELONE, Willian; MCLEAN, Ephraim. Information systems success: the quest for the dependent variable. Information Systems Research, v. 3, n. 1, p. 60-95, mar. 1992.

DENHARDT, Robert. Teoria geral da administração pública. São Paulo: Thomson; Wadsworthm, 2008.

GHOSH, Saumyendu; SKIBNIEWSKI, Miroslaw J. Enterprise resource planning systems implementation as a complex project: a conceptual framework. Journal of Business Economics and Management, v. 11, n. 4, p. 533-549, 2010.

HELMY, Yehia M.; MOHAMED, Marie I.; MOSAAD, Sara M. An integrated ERP with web portal. Advanced Computing: An International Journal, v. 3, n. 5, p. 1-8, set. 2012.

KAPLAN, Robert S.; NORTON, David. P. A estratégia em ação: balanced scorecard. Boston, MA: Harvard Business School Press, 1992.

LAUDON, Kennett C.; LAUDON, Jane P. Sistemas de informação gerenciais. São Paulo: Pearson, 2004.

LI, Eldon Y.; CHEN, Ja-Shen; HUANG, Yuan-Ho. A framework for investigating the impact of IT capability and organizational capability on firm performance in the late industrializing context. International Journal of Technology Management, v. 36, n. 1/2/3, p. 209-229, 2006.

LIMA, Gleydson et al. Interoperabilidade do infra SIG-UFRN/MJ com os sistemas estruturantes do governo federal. In: BRASIL. Ministério do Planejamento Orçamento e Gestão. Panorama da interoperabilidade no Brasil. Brasília, Secretaria de Logística e Tecnologia da Informação, 2010. p. 176-195.

MALMEGRIN, Maria L. Redes públicas de cooperação local. Florianópolis: Departamento de Ciências da Administração/UFSC; [Brasília]: Capes, UAB, 2011.

MEDEIROS JR., Alberto; PEREZ, Gilberto; SHIMIZU, Tamio. Classificação de critérios para seleção de ERP: um estudo utilizando a técnica Delphi. Revista Eletrônica de Sistemas de Informação, v. 9, n. 1, 2009, p. $1-24$.

MINTZBERG, H. et al. O processo da estratégia: conceitos, contextos e casos selecionados. 4. ed. Porto Alegre: Bookman, 2006.

MITCHELL, Victoria L. Knowledge integration and information technology project performance. MIS Quarterly, v. 30, n. 4, p. 919-939, 2006.

MORENO, José A.; GOBBO JR., José A.; CAVENAGHI, Vagner. Tecnologia da informação na gestão de cidades: um estudo de caso de implantação de ERP em um município paulista. Revista Gestão Industrial, v. 3, n. 3, p. 11-25, 2007.

MPRJ. Ministério Público do Estado do Rio de Janeiro. Diretoria de Tecnologia da Informação. Termo de Referência - Sistema Integrado de Gestão (ERP), 2013. Disponível em: <www.mprj. 
mp.br/portal_content/uploads/2013/08/Anexo-I-Termo-Refer\%C3\%AAncia.pdf>. Acesso em: 10 jul. 2014.

PAULA, Ana P. P. Administração pública brasileira entre o gerencialismo e a gestão social. Revista de Administração Eletrônica, v. 45, n. 1, p. 36-49, 2005.

SAP PORTUGAL. SAP for public sector. Disponível em: <www.sap.com/portugal/industries/publicsector/businessprocesses/index.epx>. Acesso em: 10 jul. 2014.

SILVA, Edna L.; MENEZES, Estera. M. Metodologia da pesquisa e elaboração de dissertação. 4. ed. Florianópolis: UFSC/PPGEP/LED, 2005.

SOUZA, Gleim D.; CARVALHO, Maria S. M. V.; LIBOREIRO, Manuel A. M. Gestão da cadeia de suprimentos integrada à tecnologia da informação. Rev. Adm. Pública, Rio de Janeiro, v. 40, n. 4, p. 699-729, jul./ago. 2006.

TCU. Tribunal de Contas da União. Acórdão n ${ }^{\circ}$ 2.523/2012 que trata dos sistemas informatizados de gestão das empresas estatais, 2012b. Disponível em: < http://contas.tcu.gov.br/portaltextual/ MostraDocumento?qn $=1 \& \mathrm{doc}=3 \& \mathrm{dpp}=20 \& \mathrm{p}=0>$. Acesso em: 9 nov. 2013.

TCU. Tribunal de Contas da União. Sistemas integrados de gestão das empresas estatais. In: ENCONTRO COM O MERCADO PRIVADO DE TI CONTRATAÇÕES PÚBLICAS DE TI, 2012a, Brasília. Disponível em: <http://portal2.tcu.gov.br/portal/pls/portal/docs/2515185.PDF>. Acesso em: 13 nov. 2013.

TRICATE, Heloísa. A gestão integrada na administração pública. Revista Dinâmica Pública, v. 1, n. 4, p. 74-75, 2014. Disponível em: <www.dinamicapublica.com.br/conteudo/Artigo_HeloisaTricate. html>. Acesso em: 3 jul. 2014.

TRIDAPALLI, Juarez P.; FERNANDES, Elton; MACHADO, Waltair V. Gestão da cadeia de suprimento do setor público: uma alternativa para controle de gastos correntes no Brasil. Rev. Adm. Pública, Rio de Janeiro, v. 45, n. 2, p. 401-33, mar./abr. 2011.

TURBAN, Efraim; MCLEAN, Ephraim; WETHERBE, James. Information technology for management: transforming business in the digital economy. 3. ed. Nova York: John Wiley e Sons. Inc, 2002.

VILLAS, Marcos et al. Assegurando o alinhamento estratégico da tecnologia de informação e comunicação: o caso das unidades de refino da Petrobras. Rev. Adm. Pública, Rio de Janeiro, v. 40, n. 1, p. 127-153, jan./fev. 2006.

YIN, Robert K. Estudo de caso: planejamento e métodos. Porto Alegre: Bookman, 2001.

André Souza de Sena é especialista em gestão pública pela Universidade de Brasília (UnB). E-mail: andresena1512@gmail.com.

Patricia Guarnieri é doutora em engenharia de produção, professora adjunta na Faculdade de Economia, Administração e Contabilidade, Departamento do curso de Administração, da Universidade de Brasília (UnB). E-mail: patguarnieri@gmail.com. 